\title{
Justification of the method of dust emissions localization on mobile crushing and sorting complexes of quarries with the use of air-and- water ejectors
}

\author{
Valerii Kolesnyk ${ }^{1}$, Artem Pavlychenko ${ }^{1, *}$, Olena Borysovska ${ }^{1}$, Yurii Buchavyi ${ }^{1}$, and Daria \\ Kulikova ${ }^{1}$ \\ ${ }^{1}$ Dnipro University of Technology, 49005, Dnipro, Yavornytskoho Ave., 19, Ukraine
}

\begin{abstract}
Rock mass transloading from bunkers to conveyors or from conveyors to conveyors in quarries is accompanied by intense releases of dust into the atmosphere, which is a significant danger to the environment. The regularities of the interaction process between dust particles and droplets of a liquid (water) in polluted air flow are determined. It is established that when the pressure of compressed air is changed from 0.1 to $0.4 \mathrm{MPa}$ (approximately in the range of 1 to $4 \mathrm{~atm}$.), the average size of droplets decreases from 26 to 9 microns. Justification of the localization method of dust emissions into the atmosphere, arriving from the units of dust formation in crushing and sorting complexes of quarries, is done with the use of air-and-water ejectors - irrigators with highly efficient water use, sprayed with separate nozzles. Variants of air-and-water ejectors placement on dust formation sources are grounded. The choice of the optimal mode of air-and-water ejectors operation depends on the characteristic sizes of the formed dust particles, which are determined by the parameters of the crushing and sorting equipment in the quarry. Reducing dust emissions within the sanitary protection zone of the quarries prevents its dispersion in the adjacent zone.
\end{abstract}

\section{Introduction}

Mining enterprises activity leads to the formation of significant changes and transformation of environmental objects [1-7]. Open cast mining of mineral deposits results in atmospheric air pollution [8-11], violation of the geological environment [12-16] and land [17-26], depletion and pollution of water resources [27-30], the formation of significant volumes of man-made waste [31-37], etc. Such a situation requires the improvement of methodological approaches to the comprehensive assessment and forecasting the negative effects of the enterprises' operation [35-39], the development of technological schemes for the disturbed lands recultivation and the use of mining waste [29-33], as well as the development of environmental programs and strategies for the restoration and further use of industrial region territories [33, 39-42].

\footnotetext{
*Corresponding author: pavlichenko.a.v@nmu.one
} 
Solid minerals while open cast mining usually are processed at a crushing and sorting complex, which is situated stationary on the surface of the quarry (on board a quarry or on an industrial site or mine site) [34]. The processing involves crushing the rock mass $n$ crushers, its classification and sorting on screens, the transportation of rocks by belt conveyors, their reloading from one conveyor to another, storage of break-stone goods in piles. These processes are accompanied by a significant release of dust, which, together with the dust, periodically formed during drilling and blasting works in the very quarry represents a significant danger to the environment.

In recent times, the use of mobile or transportable crushing and sorting equipment has spread. These machineries are located in the quarry at his benches, which reduces the dust escape outside the sanitary protection zone of the quarry due to a certain localization of the sources of its continuous formation and the dust deposition directly in the quarry.

Processing complexes, for example, on non-metallic pits, usually carry out one- and two-stage crushing of minerals, as well as the sorting of the obtained break-stone and sand into 4-5 fractions of grain size on the screens, which are located in the quarry in the form of a chain. In this case, the main sources of dust, in particular, on mobile systems, are [34, 4347]:

- Vibrating disintegrators of rocks (in the case of their use instead of drilling and blasting works);

- Crushing equipment, i.e. crushers (jaw, conical, rotary, etc.);

- Sorting equipment (screens of various designs);

- Places of material reloading from crushing mechanisms to conveyors, sorting and vice versa;

- Conveyor belts, which moves material and finished products between production units and mechanisms.

Taking into account the above, the purpose of the work was to substantiate the method of localization of dust emissions from the sites of dust formation at the crushing and sorting complexes of quarries with the use of hydraulic sprinklers in the form of water ejectors.

\section{State of question and statement of research problem}

The places of dust formation at the quarry processing complex are located on open areas, points of loading and overloading of minerals at short distance from each other and form a certain local chain of mobile mining equipment. At the same time, the emission of dust along this chain varies with a certain degree of cyclicity as the useful product forms and moves. In this case, it is expedient to consider the entire chain as a plane object of dust emission, instead of a separate analysis of each of its separate sources. Thus, the problem solution of the increasing of dust localization efficiency within the location of the processing complex prevents its scattering in the adjacent zone and creates the prerequisites for further size reduction of sanitary protection zone of the of mining enterprises, which is, in particular, important for granite quarries and quarries of other non-metallic and building materials, which often operate in proximity to residential buildings of cities or villages.

For effective localization of dust emissions while processing of non-metallic mineral raw materials in a quarry, dust suppression means can be used, such as irrigators with use of spray water, in which various surface-active substances are added, including synthetic surface-active substances (synthetic surfactants). However, for reasons of environmental safety, it is unwanted to use humidifiers based on or with the addition of synthetic surfactants in a free atmosphere, which are used mainly in closed spaces (buildings, mine workings or other ventilation channels). In addition, introduced into the dusty air stream, the drip fluid forms, when interacting with dust particles, a semi-liquid aerosol with a solid core (a dust particle is immersed in a drop and enveloped by a liquid), providing during 
dust suppression in a closed restricted space their rapid deposition due to a significant increase in size and mass formed as a result of coagulation of aggregates. In the free atmosphere, with the transfer of such particles in the air under the influence of wind and turbulent diffusion, their liquid shell will evaporate, or the particles will coagulate when stirred in a turbulent flow. It is obvious that the first process will reduce the rate of dust deposition and the second process will increase it.

Thus, in order to determine the real picture of the dispersion and deposition of the aerosol formed during irrigation in a free atmosphere, it is necessary to evaluate the interaction of dust particles with the droplets of the liquid spray in the moving flow and the transformation degree of disperse composition of the dust and the formed aggregates, since, in particular, the standardized method for determining the dispersion of pollutants in the atmosphere [48] in addition to the intensity of dust emissions, takes into account the indicator associated with the average size of particles emitted into the air.

\section{Methods}

We analyse the process of interaction of dust particles with droplets of a liquid (water) in a dusty air stream, using the provisions obtained on this subject, for wetting coal dust in a closed atmosphere of mine workings of mines [49]. In this case, we assume that water droplets are introduced into the stream without significant effect on the emitted dust air mixture, and without the counter resistance, which is typical for the open atmosphere, and the interaction of particles and droplets will be random.

The probability of meeting the dust particles of radius $r$ with droplets of radius $R$ is proportional to their quantities per unit volume, the effective intersection of their interaction $\pi(r+R)^{2}$, and the capture degree of particles by droplets at a certain speed of their relative motion. Then for the dust particles of the radius $r_{i}$, moving relative to droplets of the size $R_{j}$ at a speed $v_{i j}$, the change in the density of particles $d v_{i j}$ at the capture coefficient $E_{i j}$, which takes into account the efficiency of the interaction of each particle and the droplet, during infinitely small time interval $d t$ is determined by the differential equation

$$
d \mathrm{v}_{i j}=-\mathrm{v}_{i j} N_{j} \pi\left(r_{i}+R_{j}\right)^{2} v_{i j} E_{i j} d t
$$

where $r_{i}$ is the radius of the dust particles, $\mu \mathrm{m} ; R_{j}$ is the radius of water droplets, $\mu \mathrm{m} ; v_{i j}$ is the velocity of dust particles relative to water droplets, $\mathrm{m} / \mathrm{s} ; E_{i j}$ is the coefficient of capture of dust particles by water droplets, particles of unit; $v_{i j}$ and $N_{j}$ are the calculated concentrations of dust particles per unit volume, units $/ \mathrm{dm}^{3}$ interacting with the $j$-size fluid droplets, and these droplets, respectively.

Having divided the variables, we obtain

$$
\frac{d \mathrm{v}_{i j}}{\mathrm{v}_{i j}}=-N_{j} \pi\left(r_{i}+R_{j}\right)^{2} v_{i j} E_{i j} d t .
$$

The integral of this equation for the initial (prior to irrigation) calculated concentration of dust particles $v_{i j}=v_{i j}(0)$ at $t=0$ has the form

$$
P_{i j}=\frac{\mathrm{v}_{i j}}{\mathrm{v}_{i j}(0)}=\exp \left[-\pi\left(r_{i}+R_{j}\right)^{2} \int_{0}^{t} N_{j} v_{i j} E_{i j} d t\right] .
$$

Expression (2) determines the probability that a particle of radius $r_{i}$ is not captured by drops of radius $R_{j}$ for time $t$. Since the process of capturing of dust particles by drops of 
different sizes is independent, the probability that particles of $i$-th fraction will not be captured by drop of all sizes will be written as a product of the corresponding probabilities

$$
P_{i}=P_{i 1} \cdot P_{i 2} \cdots P_{i m}
$$

or

$$
P_{i}=\frac{v_{i}}{v_{i}(0)}=\exp \left[-\pi \sum_{j=1}^{m}\left(r_{i}+R_{j}\right)^{2} \int_{0}^{t} N_{j} v_{i j} E_{i j} d t\right],
$$

where $P_{j}$ is the probability that particles of the $i$-th fraction will not be trapped by droplets of all sizes, particles of unit.

It is obvious that the relative fraction of particles of $i$-th fraction of dust, which is numerically equal to $P_{i}$, will continue its movement, settling from the stream in proportion to the speed of its deposition (levitation) in the air. Caught particles whose fraction is $1-P_{i}$, make aggregates with droplets in the form of semi-liquid particles with solid core. The speed of their deposition (levitation) in the air is directly proportional to the size and mass of the formed particles; therefore, the intensity of their levitation is substantially higher.

Calculated concentrations of dust particles in the formula (3) are usually changed by mass concentrations and concentrations of droplets - by volumetric, considering them spherical

$$
\mathrm{v}_{i}=\frac{3 n_{i}}{4 \pi \rho r_{i}^{3}} ; \mathrm{v}_{i}(0)=\frac{3 n_{i}(0)}{4 \pi \rho r_{i}^{3}} ; N_{j}=\frac{3 V_{j}}{4 \pi R_{j}^{3}},
$$

where $n_{i}$ is the final, and $n_{i}(0)$ is the initial mass concentration of $i$-th fraction of dust, $\mathrm{mg} / \mathrm{m}^{3}$; $\rho$ is the dust density, $\mathrm{kg} / \mathrm{m}^{3} ; V_{j}$ volume of drops of $j$-th fraction, $\mathrm{dm}^{3} / \mathrm{m}^{3}$.

Taking into account the dispersed distribution of fractions of dust and drops, consider

$$
n_{i}(0)=\xi_{i} n(0) \text {, and } V_{j}=\psi_{j} V .
$$

where $\xi_{i}$ is the mass fraction of the $i$-th faction; $n(0)$ is initial total mass concentration of dust particles of all sizes, $\mathrm{mg} / \mathrm{m}^{3} ; \psi_{j}$ is volume fraction of drops of $j$-th fraction; $V$ is total volume concentration of droplets of all sizes, $\mathrm{dm}^{3} / \mathrm{m}^{3}\left(1 / \mathrm{m}^{3}\right)$.

Since $\frac{\mathrm{v}_{i}}{\mathrm{v}_{i}(0)}=\frac{n_{i}}{n_{i}(0)}$, the expression can be rewritten as

$$
P_{i}=\exp \left[-\frac{3}{4} \sum_{j=1}^{m} \frac{\left(r_{i}+R_{j}\right)^{2}}{R_{j}^{3}} \int_{0}^{t} V_{j} v_{i j} E_{i j} d t\right] .
$$

Here, the component $\left(r_{i}+R_{j}\right)^{2} / R_{j}^{3}$ determines the degree of dispersion of droplets, which affects the capture efficiency, i.e., its encounter with a dust particle, and the sum from 1 to $m$ characterizes the specific surface of the spray liquid.

The mass concentration of dust particles of all fractions, not captured by liquid droplets of all sizes, is represented as:

$$
P=\sum_{1}^{k} n_{i} / \sum_{1}^{k} n_{i}(0)=\sum_{1}^{k} n_{i} / n(0)=\sum_{1}^{k} P_{i} n_{i}(0) / n(0) .
$$


Substitution in the last expression of formula (5), taking into account (4), gives

$$
P=\sum_{i=1}^{k} \xi_{i} \exp \left[-\frac{3}{4} \sum_{j=1}^{m} \frac{\left(r_{i}+R_{j}\right)^{2}}{R_{j}^{3}} \int_{0}^{t} \psi_{j} V \cdot v_{i j} E_{i j} d t\right] .
$$

In relation to the solvable problem, formula (6) characterizes the relative content of the mass of dust particles in unit of air volume, which are not captured by droplets, that is, the dust that will remain dry, with the random nature of the interaction of its particles with the liquid spray in the stream. It is obvious that the value $\mathrm{v}$ will be equal to the relative content of the wetted dust. With this in mind, the problem of scattering particles in the atmosphere after irrigation of a dusty stream can be formally split into two tasks, that is, to solve separately the problem of scattering for dry and wetted dust, and the general solution can be presented as a superposition of these partial solutions.

In solving such problems, according to the standardized method of scattering aerosols in the atmosphere [49], one source of dust emissions should be replaced by two. At the same time, the emission intensity of each of them will be proportional to $P$ and $1-P$ and the average particle size should be determined accordingly for dry dust and for liquid dropletsaggregates. Moreover, it should be borne in mind that the liquid phase only affects the size of the particles and the rate of their deposition, and the actual concentration of dust, due to deposition of droplets-aggregates, must be calculated only on their solid phase, since the liquid eventually evaporates.

The practical use of the formulas obtained requires taking into account the total concentration of all drops of the spray liquid $V$, which is determined by the following factors:

- The actual disperse composition of droplets, which depends on the type of irrigator and the pressure of the liquid supplied to it;

- Calculated (mass) concentration of dust particles;

- Capture coefficient of particles by droplets;

- The performance of the irrigation system, which depends on its design.

In turn, we will analyse the following factors for their subsequent consideration.

\section{Results and discussion}

A disperse composition of droplets in a torch of a certain irrigation nozzle can be approximately estimated, for example, according to median diameters of droplets by calculation, using empirical formulas of their distribution in size. Assessment of a disperse composition of dust particles is possible on the basis of a priori data on the dispersion of dust in certain areas of crushing of the rock mass. Meanwhile, the size of the particles, both dust and droplets can be estimated experimentally directly in the flow according to the known method [50]. The scheme of the method is shown in Fig. 1. Its essence lies in the passage of a coherent (laser) beam of light through a controlled dispersion environment, and the average size of the analysed particles is evaluated by the size of the central light spot of the diffraction picture obtained on a screen spaced sufficiently from the laser. The scheme of determining the droplets size of a spray liquid, which depends on the pressure of water or air, is shown in Fig. 1.

As a source of coherent radiation, the authors used a semiconductor laser with a power of about $3 \mathrm{~mW}$ with a wavelength $\lambda=0.75 \mu \mathrm{m}$. In this case, the size of the light spot of the diffraction picture $-X$, which is visible on the screen in a darkened room, was measured at a distance of $L \approx 500 \mathrm{~cm}$, and the estimation of the average size of droplets or particles weighed in the air $(\bar{d})$ was carried out according to the formula: 


$$
\bar{d}=1.22 \frac{\lambda}{X} L, \mu \mathrm{m}
$$

where $\lambda$ - is the radiation wavelength, $\mu \mathrm{m} ; X$ - is the size of the light spot of the diffraction pattern, $\mathrm{cm} ; L-$ is the distance to the screen, $\mathrm{cm}$.

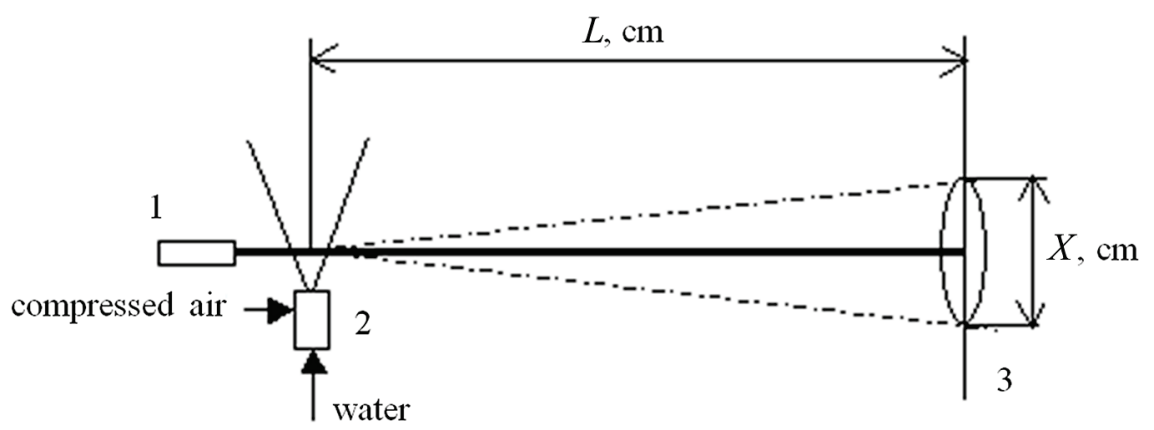

Fig. 1. Scheme for determining the droplets size of spray liquid: 1- laser emitter; 2 - water irrigator (sprayer); 3 - screen.

It was found that when the pressure of compressed air changed from 0.1 to $0.4 \mathrm{MPa}$ (approximately in the range of 1 to 4 atm.), the average size of droplets decreased from 26 to 9 microns. It is noteworthy that the major water mass of natural fog, formed in the atmosphere falls on particles of 5-15 microns, with a median diameter of about 10 microns. As you can see, it is possible to get an artificial fog, which is known to be the most effective trapper of fine (respirable) dust, by use of pneumatic nozzle with a relatively small air pressure (about $0.4 \mathrm{MPa}$ ) and at the opening of the jet nozzle twice as large as is usually recommended for fog generators, which does not require special water purification before feeding into the nozzle.

To determine a disperse composition of dust the sample dust was prepared. At the same time, the glass plate was lubricated with a thin layer of Vaseline. The plate thus prepared was placed in a dusty stream for sticking particles for a short time. The resulting dust sample was covered with a clean cover glass. Further, in laboratory conditions, the test was placed in the path of the laser beam, respectively to the scheme shown in Fig. 1, i.e. instead of a water irrigator.

Note that after evaluating the size of the particles (dust and droplets), the required value $\left(r_{i}+R_{j}\right)^{2} / R_{j}^{3}$, which is needed for formula (5) or (6) is calculated in particular, for the characteristic size of the dust particles.

The concentrations of dust particles were determined gravimetrically. It is also possible to use modern portable devices to measure dust pollution, taking into account the range of concentrations and types of dust.

Determination of the capture coefficient of dust particles with droplets of water is a more complex task. With a number of assumptions, its value is determined from the general solution of the equation of flow continuity and the equation of particle motion in the coordinate system, which is connected with the streamlined drop.

Without indicating these equations, as an example, we will map on the threedimensional graph (Fig. 2) the values of the capture coefficient of particles $E_{i j}$ by drops of water of radius $R_{j}$, boundary for typical hydro sprayers, namely: 5 and $300 \mu \mathrm{m}$, at different speeds of their mutual movement. Moreover, values of the efficiency of capturing dust particles in the diameter from 2 to 60 microns by drops are selected for displaying, which, in particular, are formed in fog generators or in the case of action of conical nozzle type KF 7.5-40 with a minimum water pressure at a relative speed of particles from 5 to $40 \mathrm{~m} / \mathrm{s}$. 

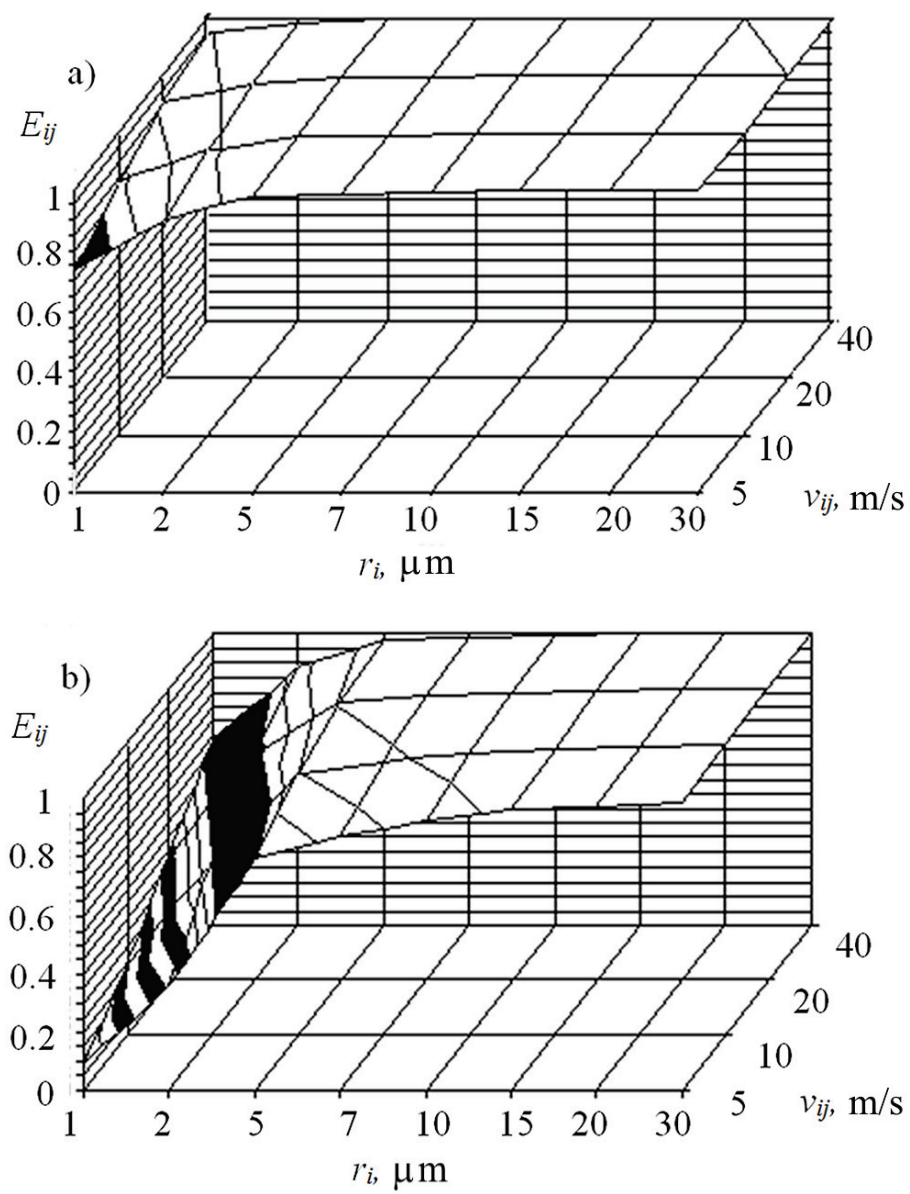

Fig. 2. Dependence of the capture efficiency of particles with different radius $r_{\mathrm{i}}$ by drops at different relative speed of their motion $v_{i j}$ : a, b - respectively for drops of radius $R_{i}=5$ and $300 \mu \mathrm{m}$ (the diameter of droplets $2 R_{j}$ is respectively 10 and $600 \mu \mathrm{m}$ ).

The analysis of dependencies presented in Figure 2 shows that the greatest interaction efficiency of particles with droplets is observed in the region of an almost horizontal plateau occupying the largest surface of a three-dimensional graph where $E_{i j}$ varies within the range of $0.95-1$. This value is typical for high relative speed, for large dust particles and for small droplets. Reducing the speed and particle size from the maximum values or increasing the size of the drops leads to the displacement of $E_{i j}$ values from this plateau into the left front area of the three-dimensional graph to a certain minimum. With an average diameter of $10 \mu \mathrm{m}$, the minimum was 0.75 for particles with a diameter of $2 \mu \mathrm{m}$ and a relative speed of $5 \mathrm{~m} / \mathrm{s}$. Moreover, the plateau occupied about $85 \%$ of the graph surface.

With a diameter of droplets of $2 R_{j}=600$ microns, the mentioned above minimum for similar boundary conditions reaches 0.1 , that is, the interaction efficiency falls almost 10 times, and the horizontal plateau occupies twice smaller area on the graph. Its left limit at a speed of $5 \mathrm{~m} / \mathrm{s}$ corresponds to particles in the size of about 25 microns. The efficiency of capturing smaller particles with such droplets becomes below 0.95 and rapidly decreases to the minimum $\left(E_{i j}=0.1\right)$ mentioned above.

High values of the relative speed of particles and droplets are observed in a sputtering torch of a nozzle when spray water is introducing into a pollinated stream. The most 
efficient interaction between them usually occurs here. At a greater distance, the droplets are picked up by the flow, gaining its speed. As a result, the relative speeds of particles and droplets in the longitudinal direction of the flow fall practically to zero. In this case, the transverse pulsating components of the flow speed are essential for the interaction of droplets and particles. Value of such transverse pulsating components at high Reynolds numbers is only slightly below the longitudinal one.

To generalize the performed theoretical analysis, the dependences of the particle capture rate on the size of the dust particles expected to arise when irrigation of the polluted air flow, whose speed is constant (Fig. 3), were calculated.

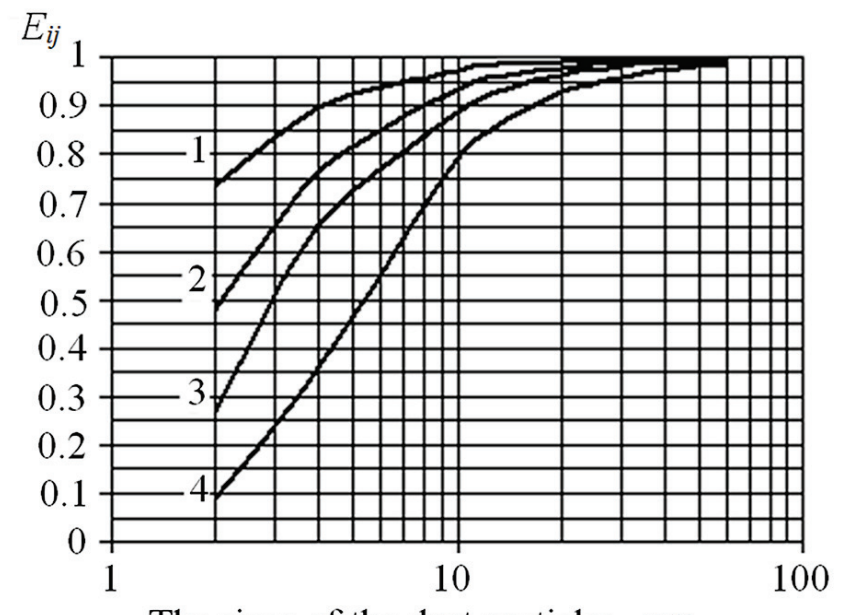

The sizes of the dust particles, $\mu \mathrm{m}$

Fig. 3. Dependences of the capture coefficient $E_{i j}$ of particles with drops from the size of particles at a relative speed of their movement of $5 \mathrm{~m} / \mathrm{s}: 1,2,3,4-$ for the diameters of drops 10;40; 100 and 600 microns, respectively.

These dependences were used to determine the size of the semi-liquid particlesaggregates and dust particles not captured by droplets, i.e. their disperse composition, as an important indicator which is necessary for the calculation of the actual scattering fields and dust deposition in the free atmosphere, both according to the standardized method [48] and according to the method developed by the authors for polydisperse particles, which is implemented in the software package "Scilab". The last method allows, by means of a computational experiment, to obtain, on a mathematical model, two-dimensional diagrams of scattering and deposition of particles in the wind direction at a certain intensity of dust emissions, $\mathrm{g} / \mathrm{s}$ (at the point with the specified territorial coordinates), wind speed, $\mathrm{m} / \mathrm{s}$, with the most characteristic diffusion coefficient, $\mathrm{m}^{2} / \mathrm{s}$, and the dispersed composition of particles.

Comparison of the diagrams of the intensity of dust emissions deposition into the atmosphere in the territory surrounding the quarry crushing and sorting complex before and after irrigation application to suppress the dust in the most dangerous production units can determine the effectiveness of dust emissions localization from the specified complex by the degree of area displacement of the highest dust intensity to the direction of this complex.

Note that the problem of scattering the total mass of dust ejected and the atmosphere at the nodes of dust formation can be represented as a superposition of partial solutions obtained separately - for the scattering of not wet (dry) and wetted parts of dust. The qualitative nature of solving the problem of dust dispersion at different distances from the dust formation site $D$ before and after hydro irrigation is shown in Figure 4. 
As you can see, the wetted part of the dust can almost completely be deposited at a distance of $150 \mathrm{~m}$ from its source, but not wetted particles continue to spread further in the direction of the wind. However, at a distance of $300 \mathrm{~m}$, which corresponds to the typical size of the sanitary protection zone (SPZ) of quarries for the extraction of non-metallic and building materials, the concentration of non-wetted dust, which is mainly fine dust, will decrease (Fig. 4) by about half and will become less than the conditional level of MPC of dust.

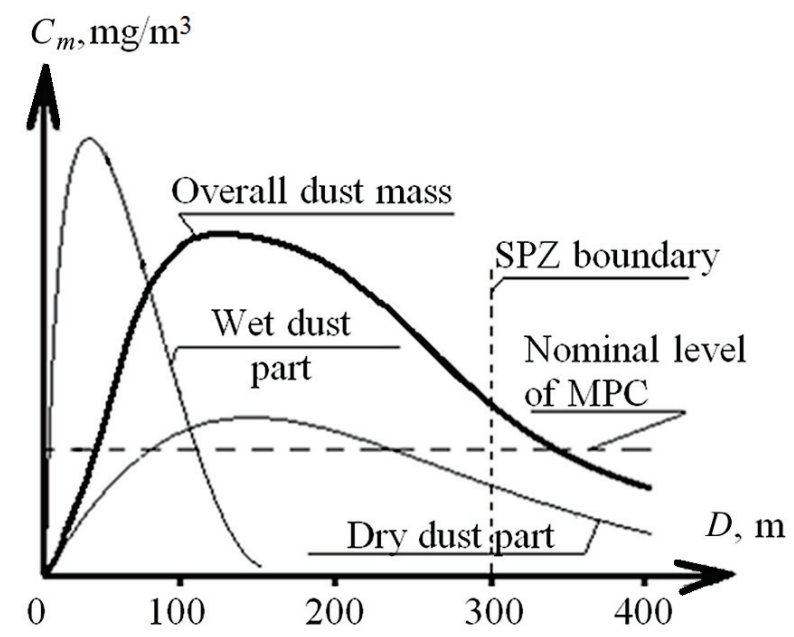

Fig. 4. The qualitative nature of the change in the surface concentration $C_{m}$ of the total dust mass released into the atmosphere at the sites of dust formation, and its components - not wet (dry) and wetted parts of dust formed in the case of dust hydro irrigation in the direction of wind.

The performed theoretical analysis showed that the higher the efficiency of the interaction of dust particles with water droplets, the smaller the wetted particle of dust becomes, which means that less dust will fall outside the SPZ of quarry. Therefore, it is necessary to improve the efficiency of hydro irrigation.

Now consider the design of the irrigation system. Perspective, in our opinion, is the use of ejector type devices for water spraying and coagulation of dust aerosols in the powdergas environment at the units of dust formation, in particular, on a quarry crushing and sorting complex. The air and water ejector (AWE) can be an example of such a device, which is a water irrigator with increased efficiency of the use of spray water (compared with a separate hydro nozzle), developed with the participation of authors for the dust suppression, including dust of non-metallic raw materials extracted in quarries, the scheme of which and the principle of action are given in [51].

It is a device in which the working fluid is water fed under pressure to the torch of the nozzles, at the outlet of which it acquires high speed and is sprayed into small droplets. Proceeding from the diffuser, the spray of the water captures (ejects) dusty air, which is sucked through the confuser and enters the diffuser, where it interacts with the sprayed (dispersed) water, i.e. there is a probabilistic process of interaction of dust particles with water droplets. Thus, conditions are formed that at the outlet of the AWE leads to intensive coagulation and deposition of the aggregate particles (liquid + dust particle).

Thus, at the outlet of the nozzle a conical water-air jet is formed, the angle of opening of which $(\alpha)$ is practically equal to the angle of the cone of the diffuser. This creates the conditions necessary for the ejection of dust-contaminated air into the receiving chamber, and for the dynamic interaction of dust particles and droplets of the spray liquid, which 
leads to intense coagulation and suppression of enlarged particles-aggregates (liquid + dust particles) at the outlet of the AWE.

Experimental studies have shown that it is advisable to use a longer (up to $30-40 \mathrm{~cm}$ ) cylindrical chamber between the diffuser and the confuser for single-phase jet devices, that is, when using one AWE. This enhances the ejection of dusty air and the dynamic interaction of dust particles with droplets. The mode of its operation is selected depending on the characteristic concentrations and sizes of dust particles, which affect the desired range of the spray torch and water flow.

The choice of the optimal mode of AWE operation depends on the characteristic sizes of the formed dust particles, which are determined by the parameters of the crushing and sorting equipment in the quarry, that is, the pressure and water flow of AWE are adjusted for each individual production unit.

As noted, the intensification of dust deposition near the dust formation units will be due to their enlargement as a result of water spraying of dust weighed in air and due to the coagulation of irrigated particles.

The use of AWE at the units of dust formation will reduce the spread of dust outside the sanitary protection zone under unfavourable meteorological conditions, when the convective transfer of atmospheric pollutants is maximal, and under favourable conditions will minimize the impact on the territory of the sanitary protection zone and, in the end, will reduce its size. Note that the AWE is mobile in design but needs a source of water with a certain pressure. As an option, it is possible to arrange tanks with liquid and pumps on a quarry complex.

\section{Conclusions}

Summing up the results of the performed justification of the localization method of dust emissions into the atmosphere, coming from the dust formation units in mobile crushing and sorting complexes of quarries, the of air-and-water ejectors - irrigators applying with highly effective use of spray water will reduce the spread of dust outside the sanitary protection zone of the quarry, will minimize the impact of dust on its territory and, in the long run, reduce the size of the sanitary protection zone.

The practical use of the presented probabilistic assessments of the interaction of water droplets with dust particles requires taking into account the disperse composition of droplets created by the AWE, the concentration of dust particles released into the atmosphere in certain units of the complex, the capture coefficient of particles by drops associated with the performance of the AWE and the factors listed, in relation to the determination of which specific recommendations and certain methods are given.

The effectiveness of the emission localization from this complex, which can be considered as a plane object of dust release, is recommended to be carried out according to the displacement area degree of the greatest concentration or deposition intensity outside it towards this complex after the use of irrigators (several air-and-water ejectors) for the dust suppression.

\section{References}

1. Myronova, I. (2015). The level of atmospheric pollution around the iron-ore mine. New Developments In Mining Engineering 2015, 193-197

2. Gomelya, M.D., Trus, I.M., Radovenchyk, I.V. (2014). Influence of stabilizing water treatment on weak acid cation exchange resin in acidic form on quality of mine water nanofiltration desalination. Naukovyi Visnyk Natsionalnoho Hirnychoho Universytetu, 
(5), 100-105

3. Adamenko, Y.O., Arkhypova, L.M., Mandryk, O.M. (2016). Territorial standard quality hidroekosystem protected areas. Hydrobiological Journal, 6(52), 51-59

4. Kirin, R. (2019). Statutory and regulatory requirements in the process of mineral mining in Ukraine. Review and analysis. Mining of Mineral Deposits. 13(2), 59-65. https://doi.org/10.33271/mining13.02.059

5. Melnyk, L., Bessarab, O., Matko, S., Malovanyy, M. (2015). Adsorption of Heavy Metals Ions from Liquid Media by Palygorskite. Chemistry and Chemical Technology, 9(4), 467-470. DOI: 10.23939/chcht09.04.467

6. Bulat, A., Voloshyn, O., Zhevzhik, O. (2013). Plasma reactor for thermochemical preparation of coal-air mixture before its burning in the furnaces. Mining of Mineral Deposits, 39-44. https://doi.org/10.1201/b16354-9

7. Voloshyn, O., Potapchuk, I., Zhevzhyk, O., Semenenko, Y., Tatarko, L. (2018). Study of the plasma flow interaction with the borehole surface in the process of its thermal reaming. Mining of Mineral Deposits, 12(3), 28-35

8. Khomenko, O., Kononenko, M., Myronova, I., Sudakov, A. (2018). Increasing ecological safety during underground mining of iron-ore deposits. Naukovyi Visnyk Natsionalno ho Hirnychoho Universytetu, (2), 29-38. DOI: 10.29202/nvngu/2018-2/3

9. Yurchenko, A., Litvinenko, A., Morozova, T. (2015). Study of dust cloud spraying parameters in terms of its suppression. New Developments in Mining Engineering 2015: Theoretical and Practical Solutions of Mineral Resources Mining, 71-74

10. Kharytonov, M., Benselhoub, A., Kryvakovska, R., Klimkina, I., Vasylyeva T. (2017). Risk assessment of aerotechnogenic pollution generated by industrial enterprises in Algeria and Ukraine. Studia Universitatis Vasile Goldis Arad, Seria Stiintele Vietii, 27(2), 99-104

11. Vambol, S., Vambol, V., Bohdanov, I., Suchikova, Y., Rashkevich, N. (2017). Research of the influence of decomposition of wastes of polymers with nanoinclusions on the atmosphere. Eastern-European Journal of Enterprise Technologies, 6, 10(90), 57-64. doi: 10.15587/1729-4061.2017.118213

12. Lozynskyi, V., Saik, P., Petlovanyi, M., Sai, K., Malanchyk, Ye. (2018). Analytical Research of the Stress-Deformed State in the Rock Massif Around Faulting. International Journal of Engineering Research in Africa, (35), 77-88. https://doi.org/10.4028/www.scientific.net/JERA.35.77

13. Voloshyn, O.I., Potapchuk, I.Yu., Zhevzhyk, O.V. (2018). Influence of the heat-transfer stream pressure on the surface of the rock in a process of the thermal reaming of the borehole. Naukovyi Visnyk Natsionalnoho Hirnychoho Universytetu, (2), 53-59. http://dx.doi.org/10.29202/nvngu/2018-2/6

14. Khomenko, O.Ye. (2012). Implementation of energy method in study of zonal disintegration of rocks. Naukovyi Visnyk Natsionalnoho Hirnychoho Universytetu, (4), 44-54. https://doi.org/10.29202/nvngu

15. Rakishev, B.R., Seituly, K., Kovrov, O.S. (2015). Physical modeling geomechanical stability of open-cast slopes and internal overburden dumps. Legislation, Technology and Practice of Mine Land Reclamation - Proceedings of the Beijing International Symposium Land Reclamation and Ecological Restoration, LRER 2014, 583-588

16. Voloshyn, O., Potapchuk, I., Zhevzhyk, O., Zhovtonoha, M. (2018). Results of the experimental research of the heat-transfer jet pressure to the rock surface during thermal reaming of the borehole, E3S Web of Conferences, (60), 00024. https://doi.org/10.1051/e3sconf/20186000024

17. Gumenik, I.L., Lozhnikov, O.V., Panasenko, A.I. (2013). Deliberate Dumping Technology for Mining Reclamation Effectiveness Improvement. Naukovyi Visnyk Natsionalnoho Hirnychoho Universytetu, (5), 48-53 
18. Zadorozhnaya, G.A., Andrusevych, K.V., Zhukov, O.V. (2018). Soil heterogeneity after recultivation: ecological aspect. Folia Oecologica, (45), 46-52. doi: 10.2478/foecol2018-0005

19. Cherniaiev, O.V. (2017). Systematization of the hard rock non-metallic mineral deposits for improvement of their mining technologies. Naukovyi Visnyk Natsionalnoho Hirnychoho Universytetu, (5), 11-17

20. Gumenik, I., Lozhnikov, A., Maevskiy, A. (2012). Methodological principles of negative opencast mining influence increasing due to steady development. Geomechanical Processes during Underground Mining: School of Underground Mining 2012, 45-49

21. Prokopenko, V.I., Litvinov, Yu.I. (2017). Environmental orientable imperative of developing the technology and excavation of horizontal fields. Naukovyy visnyk Natsionalnoho Hirnychoho Universytetu, (2), 51-57

22. Kalybekov, T., Rysbekov, K., Zhakypbek Y. (2015). Efficient land use in open-cut mining. New Developments in Mining Engineering 2015: Theoretical and Practical Solutions of Mineral Resources Mining, 287-291

23. Gumenik, I., Lozhnikov, O. (2015). Current condition of damaged lands by surface mining in Ukraine and its influence on environment. New Developments in Mining Engineering 2015: Theoretical and Practical Solutions of Mineral Resources Mining, 139-143

24. Mormul, T.M., Terekhov, Ye.V. (2017). Environmental and economic estimation of technological solutions in terms of land resource conservation in the process of opencast mining. Naukovyi Visnyk Natsionalnoho Hirnychoho Universytetu, (3), 122-128

25. Terekhov, Ye.V., Litvinov, Yu.I. (2018). Eco-oriented management of manufacturing and supply activity of manganese ore raw materials supplier. Naukovyi Visnyk Natsionalnoho Hirnychoho Universytetu, 4, 166-174. DOI: 10.29202/nvngu/2018-4/20

26. Ryabchii, V.A., Ryabchii, V.V., Trehub, M.V., Trehub, Yu.Ye. (2017). Substantiation of land parcel configuration in buffer zones. Naukovyi Visnyk Natsionalnoho Hirnychoho Universytetu, (4), 80-85. DOI: https://doi.org/10.29202/nvngu

27. Zelenko, Y., Malovanyy, M., Tarasova, L. (2019). Optimization of heat-and-power plants water purification. Chemistry and Chemical Technology. 13, (2), 218-223. https://doi.org/10.23939/chcht13.02.218

28. Modoi, O.C., Roba, C., Török, Z., Ozunu, A. (2014). Environmental risks due to heavy metal pollution of water resulted from mining wastes in NW Romania. Environmental Engineering and Management Journal, 13, (9), 2325-2336

29. Kvaterniuk, S., Pohrebennyk, V., Petruk, V., Kvaterniuk, O., Kochanek, A. (2018). Mathematical modeling of light scattering in natural water environments with phytoplankton particles. 18th International Multidisciplinary Scientific GeoConference Surveying Geology and Mining Ecology Management, SGEM, 18 (2.1), 545-552. https://doi.org/10.5593/sgem2018/2.1

30. Sobko, B., Haidin, A., Lozhnikov, O., Jarosz, J. (2019). Method for calculating the groundwater inflow into pit when mining the placer deposits by dredger. E3S Web of Conferences, 123, 01025. https://doi.org/10.1051/e3sconf/201912301025

31. Kuz'menko, O., Petlyovanyy, M., Stupnik, M. (2013). The influence of fine particles of binding materials on the strength properties of hardening backfill. Annual ScientificTechnical Collection Mining of Mineral Deposits, 45-48. DOI: 10.1201/b16354-10

32. Pactwa, K., Woźniak, J. (2017). Environmental reporting policy of the mining industry leaders in Poland. Resources Policy, 53, (C), 201-207. DOI: 10.1016/j.resourpol.2017.06.008

33. Gorova, A., Pavlychenko, A., Kulyna, S., Shkremetko, O. (2012). Ecological problems of post-industrial mining areas. Geomechanical Processes During Underground 
Mining, 35-40. https://doi.org/10.1201/b13157-7

34. Dryzhenko, A., Shustov, A., Moldabayev, S. (2017). Justification of parameters of building inclined trenches using belt conveyors. 17th International Multidisciplinary Scientific GeoConference SGEM 2017, 471-478. DOI:10.5593/sgem2017/13/S03.060

35. Popovych, V., Kuzmenko, O., Voloshchyshyn, A., Petlovanyi, M. (2018). Influence of man-made edaphotopes of the spoil heap on biota. E3S Web of Conferences. 60, 00010. https://doi.org/10.1051/e3sconf/20186000010

36. Vambol, S., Vambol, V., Sundararajan, M., Ansari, I. (2019). The nature and detection of unauthorized waste dump sites using remote sensing. Ecological Questions, 30, 3(3). https://doi.org/10.12775/EQ.2019.018

37. Petlovanyi, M., Kuzmenko, O., Lozynskyi, V., Popovych, V., Sai, K. Saik, P. (2019). Review of man-made mineral formations accumulation and prospects of their developing in mining industrial regions in Ukraine. Mining of Mineral Deposits, 13, (1), 24-38. https://doi:10.33271/mining13.01.024

38. Medvedeva, O. (2015). Development and exploitation of storages of enrichment process wastes as anthropogenic deposits. New Developments in Mining Engineering 2015: Theoretical and Practical Solutions of Mineral Resources Mining, 567-573

39. Shmandiy, V.M., Kharlamova, E.V., Rigas, T.E. (2015). The study of manifestations of environmental hazards at the regional level. Gigiena $i$ Sanitariya, (7), 90-92

40. Sarycheva, L. (2003). Using GMDH in ecological and socio-economical monitoring problems. Systems Analysis Modelling Simulation, 43(10), 1409-1414. https://doi.org/10.1080/02329290290024925

41. Smol, M., Kulczycka, J., Avdiushchenko, A. (2017). Circular economy indicators in relation to eco-innovation in European regions. Clean Technologies and Environmental Policy, 19, (3), 669-678. https://doi.org/10.1007/s10098-016-1323-8

42. Gorova, A., Pavlychenko, A., Borysovs'ka, O. (2013). The study of ecological state of waste disposal areas of energy and mining companies. Mining of Mineral Deposits. CRC Press, 169-171. https://doi.org/10.1201/b16354-30

43. Belmas, I., \& Kolosov, D., (2011). The stress-strain state of the stepped rubber-rope cable in bobbin of winding. Technical and Geoinformational Systems in Mining: School of Underground Mining 2011. 211-214

44. Belmas, I., Kogut, P., Kolosov, D., Samusia, V., Onyshchenko, S. (2019). Rigidity of elastic shell of rubber-cable belt during displacement of cables relatively to drum. International Conference Essays of Mining Science and Practice. 109, 00005. DOI: $10.1051 / \mathrm{e} 3$ sconf $/ 201910900005$

45. Kolosov, D., Dolgov, O., Bilous, O., Kolosov, A. (2015). The stress-strain state of the belt in the operating changes of the burdening conveyor parameters. New Developments in Mining Engineering 2015: Theoretical and Practical Solutions of Mineral Resources Mining, 585-590

46. Bondarenko, A.O. (2018). Modeling of interaction of inclined surfaces of a hydraulic classifier with a flow of solid particles. Naukovyi Visnyk Natsionalnoho Hirnychoho Universytetu, (4), 13-20. DOI: 10.29202/nvngu/2018-4/5

47. Bulat, A.F., Dyrda, V.I., Lysytsya, M.I., Grebenyuk, S.M. (2018). Numerical simulation of the stress-strain state of thin-layer rubber-metal vibration absorber elements under nonlinear deformation. Strength Mater, 50, (3), 387-395

48. Metodika rascheta koncentracii v atmosfernom vozdukhe vrednihkh vethestv, soderzhathikhsya v vihbrosakh predpriyatiyj. (1987). OND-86. Goskomgidromed. Leningrad, Gidrometeoizdat

49. Kolesnik, V.Ye, Pavlichenko, A.V., Buchavy, Yu.V. (2016). Determination of dynamic parameters of dust emission from a coal mine fang. Naukovyi Visnyk Natsionalnoho Hirnychoho Universytetu, (2), 81-87 
50. Kouzov, P.A. (1987). Fundamentals of dispersed composition' analysis of industrial dust and crushed materials. Leningrad: Himija

51. Kolesnyk, V., Pavlychenko, A., Borysovska, O., Boyarkin M. (2018). Study of features of air-and-water ejectors use for reducing dust formation during transportation of mined rock in quarries. Scientific and technical journal Techogenic and ecological safety, 4, (2), 105-111 